УДК 796.052.2: 796.332

https://doi.org/10.36906/FKS-2021/87

Самоловов Н.А.

ORCID: 0000-0001-7619-0873, канд. пед. наук;

Самоловова Н.В.

ORCID: 0000-0002-9159-7871, канд. пед. наук Нижневартовский государственный университет,

г. Нижневартовск, Россия

\title{
ОСОБЕННОСТИ РАЗВИТИЯ СКОРОСТНЫХ СПОСОБНОСТЕЙ ШКОЛЬНИКОВ, ЗАНИМАЮЩИХСЯ БОКСОМ
}

Аннотация. Рассмотрены особенности развития скоростных способностей школьников, занимающихся боксом. Составлены комплексы упражнений для улучшения скоростных способностей. Организована апробация эффективности разработанных комплексов упражнений по улучшению скоростных способностей школьников 12-13 лет, занимающихся боксом на внеурочных занятиях.

Ключевые слова: бокс; скоростные способности; комплексы упражнений; внеурочные занятия.

Samolovov N.A.

ORCID: 0000-0001-7619-0873, Ph.D.;

Samolovova N.V.

ORCID: 0000-0002-9159-7871, Ph.D.

Nizhnevartovsk state University,

Nizhnevartovsk, Russia

\section{FEATURES OF THE DEVELOPMENT OF HIGH-SPEED ABILITIES OF SCHOOLCHILDREN ENGAGED IN BOXING}

Annotation. The features of the development of high-speed abilities of schoolchildren engaged in boxing are considered. Sets of exercises have been compiled to improve speed abilities. The testing of the effectiveness of the developed sets of exercises to improve the speed abilities of 12-13-year-olds engaged in boxing in extracurricular classes has been organized.

Keywords: boxing; speed abilities; exercise complexes; extracurricular activities.

Бокс - это олимпийский контактный вид спорта (единоборство), в котором разрешены удары только кулаками и только в специальных перчатках. Быстрота - возможность совершать движения либо действия с высокой скоростью благодаря подвижности нервно-мышечных процессов. Быстрота действий боксера включает в себя скорость движений, быстроту и частоту их двигательной реакции $[1 ; 3]$.

Ю.Ф. Курамшин считает, что в связи с множественностью форм проявления быстроты движений и высокой их специфичностью, термин быстроты необходимо заменить на понятие «скоростные способности» [1].

Способность организма спортсмена к успешной адаптации в экстремальных условиях, к которым относится опасность нокаутирования, требует от боксера максимально развитых скоростных способностей. Поэтому сейчас является актуальным подбор средств и методов для 
развития скорости боксеров, которые будут соответствовать возрасту и уровню подготовленности спортсменов. Подготовка квалифицированных боксеров требует массового вовлечения для занятий данным видом спорта подростков и молодежи, обучающихся в школе. Согласно возрастной периодизации «условным» периодом, когда меняются темпы роста и развития организма, является 11-14 лет. В этом возрасте для развития скоростных способностей необходимы различные средства физического воспитания. У мальчиков в этот возрастной период благодаря особенностям ЦНС сохраняется предрасположенность к скоростно-силовым упражнениям [2].

Цель исследования: повысить уровень развития скоростных способностей школьников, занимающихся боксом. Объект исследования: учебный процесс юношей в возрасте 12-13 лет, занимающихся боксом. Предмет исследования: скоростные способности юношей, занимающихся боксом. Гипотеза исследования: следует полагать, что комплекс упражнений, который был специально разработан для юношей 12-13 лет, позволит повысить уровень скоростной подготовленности юных боксеров, что, в свою очередь, положительно скажется на их спортивных результатах. Практическая значимость работы заключается в возможности использования полученных знаний в своей профессиональной практике учителя или тренерапреподавателя. В начале работы были поставлены следующие задачи: произвести анализ литературы по теме работы; определить упражнения, которые будут объединены в специально разработанный комплекс и помогут улучшить скоростные способности боксеров 12-13 лет; составить и определить эффективность составленного комплекса упражнений по улучшению скоростных способностей боксеров, внедрить его в учебный процесс; поставленные задачи решались с помощью следующих методов; анализ научной и методической литературы; контрольные испытания; педагогический эксперимент; метод математической статистики.

Научная и методическая литература была выбрана в связи с особенностью исследования. Мы проводили анализ литературы по теме развития скоростных способностей боксеров подросткового возраста, а так же дополнительно проанализировали программный материал и методические рекомендации. Контрольные испытания проводились в форме тестирования. В ходе исследования нами было проведено первичное (перед началом педагогического эксперимента) и повторное (по окончании педагогического эксперимента) тестирование для юношей, занимающихся боксом на внеурочных занятиях. Уровень развития скоростных способностей подростков определялся по четырем тестам:

Бег на 30 м (сек);

Прыжки со скакалкой за 30 сек (кол-во раз);

Лазание по канату на скорость (сек);

Челночный бег $3 \times 10$ (сек).

Педагогический эксперимент. Педагогический эксперимент проводился для школьников 12-13 лет, занимающихся на внеурочных занятиях боксом на базе общеобразовательной школы г.Нижневартовска. Для юношей был специально разработан и внедрен в занятия комплекс упражнений по улучшению их скоростных способностей. Исследование проводилось с 1 ноября 2020 г. по 15 января 2021 г. В эксперименте приняли участие 24 занимающихся.

Метод математической статистики. При помощи данного метода нами были обработаны результаты первичного и повторного тестирований проводимых до и после эксперимента.

В ходе первого этапа исследования мы изучали научную и методическую литературу, соответствующую теме изысканий, отобрали упражнения, способствующие улучшению показателей скоростных способностей, которые далее объединили в комплекс. 
Исходя из результатов первого тестирования занимающиеся поделились на контрольную и экспериментальную группы. К экспериментальной группе мы отнесли юношей с более слабой физической подготовленностью.

Эксперимент проводился с целью выявить эффективность комплекса упражнений, который предположительно должен был способствовать повышению уровня скоростной подготовленности боксеров 12-13 лет. Она была проведена для спортсменов, входящих в состав экспериментальной группы, юноши же контрольной группы занимались стандартно.

Наш разработанный комплекс проводился преимущественно в спортивном зале, а так же в боксерском зале со специализированным оснащением. При занятиях использовался следующий инвентарь: набивной мяч с весом 1 килограмм, канаты, утяжелители весом 1кг, боксерские груши, скакалки и прочее. Упражнения подбирались так, чтобы воспитанникам не приходилось задумываться о технической стороне или сложности выполнения задания.

На заключительном этапе исследования было проведено повторное тестирование, благодаря которому была выявлена положительная динамика в развитии скоростных способностей у экспериментальной группы боксеров 12-13 лет. На этом этапе были подсчитаны результаты исследования.

Сравнив и проанализировав результаты тестирований стало очевидно, что разработанный комплекс упражнений помог улучшить скоростные показатели занимающихся.

«Бег на 30 м»:

- контрольная группа - результаты изменились незначительно;

- экспериментальная группа - улучшение на 04, сек.

«Прыжки со скакалкой 30 сек»:

- контрольная группа - улучшение на 2 раза;

- экспериментальная группа - улучшение на 5 раз.

«Лазание по канату на скорость»:

- контрольная группа - улучшение на 3 сек;

- экспериментальная группа - улучшение на 4 сек.

«Челночный бег $3 \times 10 »:$

- контрольная группа - улучшение на 0,1 сек;

- экспериментальная группа - улучшение на 0,3 сек.

Показатели прироста физических качеств подсчитывались по формуле Brody.

Эффективность реализации тренировочной программы выразилась в следующих показателях:

- бег на 30 м: контрольная группа - результат не изменился, экспериментальная группа - улучшение на 7,2\%;

- прыжки со скакалкой 30 сек: контрольная группа - результат улучшился на 4,3\%, экспериментальная группа - улучшение на 10,9\%;

- лазание по канату на скорость: контрольная группа - улучшение на 8,9\%, экспериментальная группа - улучшение на 11,4\%;

- челночный бег 3 х10 м: контрольная группа - результат улучшен на $1,2 \%$, экспериментальная группа - улучшение на $3,6 \%$.

Исходя из результатов тестирования, можно сделать вывод об эффективности разработанного комплекса упражнений, направленного на улучшение скоростных способностей боксеров 12-13 лет.

Таким образом, по результатам исследования можно сделать следующие выводы. 
В ходе долгого времени термином «быстрота» характеризуют возможность человека выполнять максимально скоростные двигательные действия.

Быстротой называют комплекс функциональных свойств человека, которые непосредственно определяют скоростные характеристики движений и двигательные реакции $[1 ; 4]$.

Скоростные качества обычно рассматриваются как самостоятельное физическое качество человека, требующее адекватных средств и методов развития.

Анализируя результаты исследования напрашивается вывод, что результат внеурочных занятий имеет прямую зависимость от хорошо развитых скоростных способностей боксеров.

Комплекс предложенных нами упражнений содержит задания, которые довольно легко воспринять, они уже достаточно хорошо знакомы спортсменам, что помогает выполнять упражнения не задумываясь о деталях выполнения.

Анализ результатов тестов экспериментальной и контрольной групп до и после экспериментальной работы подтверждает эффективность отобранных упражнений, которые способствуют улучшению скоростной подготовки боксеров 12-13 лет. Улучшения результатов контрольного теста экспериментальной группы полностью подтверждает целесообразность внедрения разработанного комплекса упражнений.

\section{Литература}

1. Курамшин Ю.Ф., Григорьев В.И., Латышева Н.Е. и др. Теория и методика физической культуры. М.: Советский спорт, 2004. 463 с.

2. Пащенко А.Ю., Волков Л.А. Возрастные особенности физического развития школьников при занятиях спортом // Перспективные направления в области физической культуры, спорта и туризма: Материалы VI Всероссийской научно-практической конференции с международным участием. Нижневартовск, 17-18 марта 2016 года. Нижневартовск: Нижневартовский государственный университет, 2016. С. 324-328.

3. Самоловов Н.А., Шарифов А.Ф. Физическая подготовка боксеров, занимающихся в учебно-тренировочных группах // Перспективные направления в области физической культуры, спорта и туризма: Материалы VII Всероссийской научно-практической конференции. Нижневартовск, 17-18 марта 2017 года. Нижневартовск: Нижневартовский государственный университет, 2017. С. 245-249.

4. Филатова В.Ю., Самоловов Н.А. Анализ силы удара руками в кикбоксинге // Вестник Нижневартовского государственного университета. 2016. № 1. С. 91-94.

(C) Самоловов Н.А., Самоловова Н.В., 2021 